\title{
O JOVEM NO BRASIL NUNCA É LEVADO A SÉRIO
}

\author{
YOUNG PEOPLE IN BRAZIL ARE NEVER TAKEN SERIOUSLY
}

\author{
Chris Royes Schardosim \\ Doutora em Linguística \\ Universidade Federal de Santa Catarina - UFSC \\ Florianópolis, Santa Catarina - Brasil \\ chris.schardosim@ifc.edu.br \\ Renata Lewandowski Montagnoli \\ Especialista em História \\ Centro Universitário de Brusque - UNIFEBE \\ Brusque, Santa Catarina - Brasil \\ renata.lemon@hotmail.com
}

Jonatas Rubens Tavares

Especialista em Metodologia do ensino de língua portuguesa e literatura Centro Universitário Leonardo da Vinci - UNIASSELVI Indaial, Santa Catarina - Brasil jonatas.rtavares@outlook.com

\begin{abstract}
Resumo: Este artigo tem por objetivo analisar a categoria social juventude na atual conjuntura brasileira. Para tanto, busca compreender: o que é ser jovem e o que é ser jovem em contexto escolar violento. Os principais autores que ajudaram a embasar a discussão foram: Castro (2002), Groppo (2004), D’Agostini; Nogara Junior; Marcassa (2017, 2019), Andrade; Farah Neto (2007) e Ponce (2000). Para responder aos objetivos foi realizada uma pesquisa bibliográfica de caráter exploratório, conforme os conceitos dos autores Severino (2007) e Gil (2008). Ao final do artigo foi possível compreender que a sociedade não deve comparar os jovens da atualidade com as juventudes do passado, que a violência a que os jovens são submetidos nas áreas periféricas é, ainda, um desafio a ser vencido e que a escola deve buscar formas de não reproduzir a violência e tem papel fundamental no desenvolvimento de um jovem protagonista e apto para a vivência social.
\end{abstract}

Palavras-chave: juventude; violência; educação; exclusão social.

Abstract: This article aims to analyze the social category of youth in the current Brazilian context. To this end, it seeks to understand - in a conceptual way - what it is to be young and what it is to be young in a violent school context - covering the role of the school in face of this issue. The main authors who helped to base the discussion were: Castro (2002), Groppo (2004), D’Agostini; Nogara Junior; Marcassa (2017, 2019), Andrade; Farah Neto (2007) and Ponce (2000). To answer the objectives, an exploratory bibliographic research was carried out, according to the concepts of the authors Severino (2007) and Gil (2008). At the end of the article, it was possible to understand that society should not compare young people today with the youth of the past, that the violence that young people are subjected to in the peripheral areas is still a challenge to be overcome and that the school must seek ways of not reproducing violence and that it also has a fundamental role in the development of the youth as protagonist and able for social experience.

Keywords: youth; violence; education; social exclusion.

Para citar - ABNT NBR 6023:2018

SCHARDOSIM, Chris Royes; MONTAGNOLI, Renata Lewandowski; TAVARES, Jonatas Rubens. O jovem no Brasil nunca é levado a sério. Cadernos de Pós-graduação, São Paulo, v. 20, n. 2, p. 28-36, jul./dez. 2021. Disponível em: https://doi.org/10.5585/cpg.v20n2.19968. 
Eu vejo na TV o que eles falam sobre o jovem não é sério

O jovem no Brasil nunca é levado a sério Eu vejo na TV o que eles falam sobre o jovem não é sério, não é sério (CHORÃO; CHAMPIGNON; PELADO; NEGRA LI, 2000).

Introdução

Juventude é uma categoria em constante transformação. Sobre essa categoria, recaem expectativas em relação ao futuro, cobranças e responsabilidades provenientes de uma visão adulta de mundo. A juventude brasileira além de viver essas constantes transformações, também enfrenta problemas recorrente da violência - que é um problema nacional - principalmente a violência. Jovens moradores de áreas periféricas e imersos em contextos escolares violentos estão sujeitos a sérios riscos diários à sua integridade física e emocional, comprometendo o seu desenvolvimento e a vida desses sujeitos, como o refrão da música explicita: o jovem no Brasil não é levado a sério.

Pensando nos jovens e nas características que compõem essa categoria, este artigo objetiva analisar a juventude na atual conjuntura brasileira, abordando o ser jovem - em viés conceitual, e o ser jovem em contexto escolar violento. Para tanto, realizou-se pesquisa bibliográfica, aquela que, para Severino (2007), faz uso das contribuições de outros autores, disponibilizadas por meio de livros, artigos e etc. Essa pesquisa tem caráter exploratório, sendo essas as que "[...] são desenvolvidas com o objetivo de proporcionar visão geral, de tipo aproximativo, acerca de determinado fato" (GIL, 2008, p. 27). Os autores Castro (2002), Groppo (2004) e Ponce (2000) foram a literatura base empregada no desenvolvimento do presente trabalho.

Analisando essas problemáticas da juventude, o artigo percorrerá conceitos que definem a categoria, buscando identificar suas características, além de ressaltar um dos problemas que envolve e compromete o ser jovem: a violência. Os conceitos de violências aqui trabalhados serão os expostos por Castro (2002), que demonstram como a violência cerceia a vida dos nossos jovens. Trilhando esse caminho, chegaremos ao contexto escolar, que muitas vezes reproduz a violência que ocorre contra os jovens.

\section{O Ser Jovem}

Ser jovem nos tempos atuais perpassa por viver sobre a aurora de um futuro que está por chegar e esperar dele o que há de melhor. No relatório apresentado pelos Institutos iBase e Pólis, publicado no Relatório Nacional Brasil: Pesquisa sobre juventudes no Brasil, existe uma imprecisão quanto à definição da passagem da juventude para a fase adulta. Alguns entendem que ocorre no “decorrer dos vinte anos", segundo Abramo, Souto, Nascimento e Facchini (2009, p. 70): “[...] cabe reparar que o próprio termo 'juventude' nem sempre, ou não para todos, indica necessariamente uma fase específica da vida, podendo ser pensado como um atributo ou um sentimento que pode 
estar presente em qualquer idade [...]". Para D’Agostini, Nogara Junior e Marcassa (2019, p. 432 apud Marcassa, 2017, p. 14) a juventude é uma categoria social que pode ser definida:

[...] ao mesmo tempo, pela heterogeneidade e pelo agrupamento, pela diversidade e pela semelhança, portanto, marcada por determinações de classe, gênero, etnia e também clivada por diferenças produzidas pelas condições educacionais e culturais, pelo local de moradia e pela relação que estabelece com outras gerações, em especial com o mundo adulto e sua entrada nele. Por isso, é importante compreender as experiências concretas nas quais a juventude se produz, articulando expectativas, o ambiente cultural, trajetórias, modos de pensar e agir com as condições materiais e concretas nas quais esses jovens estão inseridos.

Os autores levantam vários fatores para definir a categoria juventude, para Carrano (2000, p. 11), é "[...] definida por critérios relacionados com as ideias que vinculam a cronologia etária com a imaturidade psicológica. A irresponsabilidade seria outro atributo da situação social de jovialidade, particularmente nas idades correspondentes à adolescência”. Já Abramo, Souto, Facchinni e Nascimento (2009, p. 20) levantam o questionamento: “o que define a condição juvenil?” Para eles, alguns marcos de transição é que permitem essa definição, como:

[...] a conclusão da formação escolar; a inserção na vida produtiva; a independência e autonomia em relação à família de origem, e constituição de nova família, normalmente associada ao estabelecimento de domicílio próprio, ao casamento e nascimento do primeiro filho.

Portanto, analisar a juventude é entender que "Os jovens ainda não têm os valores e comportamentos esperados como algo introjetado em sua personalidade e no modo de ser" (GROPPO, 2004, p. 16), portanto, não se pode esperar deles algo que ainda não construíram em sua constituição humana. O jovem se constitui como tal através das várias relações que estabelece, uma vez que a juventude é um elemento estrutural. Essas relações estruturais que decorrem " [...] toda sociedade e cultura diferenciam seus membros pelo gênero (masculino e feminino), pelo parentesco (mais e menos parentes) e em 'fases da vida' (infância, maturidade e velhice, geralmente com rituais de passagem entre as fases)". (GROPPO, 2004, p. 12)

A categoria juventude, segundo Carrano (2000), é permeada por um antagonismo que a coloca numa posição em que são esperados comportamentos adultos sem considerar as suas necessidades no tocante a cuidados da família, escola e Estado, além de não levar em conta as renovações da sociedade e das tradições. Ainda dentre os antagonismos que cercam o ser jovem, permeia esta categoria a ideia de que o problema da juventude atual é o excesso de liberdade, pois é estabelecida uma comparação entre a liberdade da juventude atual, com a liberdade (ou falta dela) das gerações anteriores. Esse excesso de liberdade da juventude é pontuado por Ponce (2000, p. 90): Ela tem sido tanto exaltada como condenada, mas muito pouco aprofundada como um dos 
conceitos fundamentais da ética. 'O mal do mundo de hoje é que os jovens têm muita liberdade, no meu tempo não era assim...', dizem alguns. Há em expressões como essas, uma nostalgia de um tempo menos flexível. Será que era mesmo melhor quando as regras eram mais inflexíveis?

Diante dessas tentativas de retomada de tempos longínquos, costuma-se avaliar a juventude sob uma ótica daquilo que foi referência em uma época passada. Mas esse tempo não cabe mais no presente, pois os sujeitos atuais têm outros valores, a sociedade está constituída de outra maneira, assim o saudosismo de outrora não se faz pertinente nos prejulgamentos feitos em relação aos jovens. Portanto, de acordo com D’Agostini, Nogara Junior e Marcassa (2017, p. 143): “A falta de autonomia financeira e o desemprego contribuem para que os jovens permaneçam mais tempo com seus pais, conceito este conhecido como moratória, consequentemente ampliando as crises de gerações e os demais conflitos." Segundo Abramo, Souto, Facchinni e Nascimento (2009, p. 21), muitos estudos “[...] apontam um processo de extensão da moratória, dada pela extensão do período formativo e pela dificuldade de entrar no mercado de trabalho, obrigando os jovens a uma moratória mais longa."

Por conseguinte, as relações geracionais, além de estarem enredadas em situações de condutas morais, também estão no campo financeiro, pois o que habita o imaginário dos mais velhos é aquele saudosismo de quando as crianças começavam a trabalhar desde muito cedo para auxiliar no sustento da casa, sendo algo normal naquele momento histórico. Todavia, os conceitos e valores das categorias trabalho e infância foram remodelados e o que antes era visto como algo aceitável, hoje entendemos como algo que fere o desenvolvimento saudável do sujeito. Ao trabalhar juventude e passagem do tempo, Ponce (2000, p. 94) especifica a existência de um saudosismo quanto aos valores da juventude do tempo passado:

\footnotetext{
O saudosismo dos tempos em que a obediência à hierarquia dos 'mais velhos, mais experientes e sábios' era valorizada desvaloriza os jovens e os coloca em uma posição de impotência diante do seu tempo. Será que essa atitude é educativa?

Durante várias gerações, pais e professores educaram seus filhos e alunos como foram educados, e o modelo de educação estava à mão, disponível e próximo para ser utilizado como tal, nas famílias e nas escolas.

É um modelo que, felizmente, não tem mais razão para continuar em vigor, pois ele omite e não desenvolve a dimensão da liberdade.
}

Fica evidente que cada sociedade é fruto do seu tempo. Portanto, a juventude atual tem seus próprios anseios e sobre ela recaem as muitas expectativas de uma sociedade adultizada, que a vê como "[...] uma constante preocupação das sociedades modernas e contemporâneas, uma permanente 'questão pública"' (GROPPO, 2004, p. 10). Além disso, há o contexto e suas mudanças: 
O contexto sociopolítico e econômico promoveram mudanças socioculturais que possibilitam maior liberdade e autonomia decorrentes da diminuição da autoridade e controle dos pais e da escola. o maior controle sobre os jovens agora está sob a tutela da realidade material de produção da vida, que acaba por limitar não só os jovens mas também toda a classe trabalhadora. (D’AGOSTINI; NOGARA JUNIOR; MARCASSA, 2017, p. 142)

Toda a carga de expectativas e reservas de que os jovens são alvos pode acabar por atrasar ou intervir na formação de um cidadão protagonista, ativo socialmente. Barber-Madden e Saber (2016) defendem a importância de se confiar nos jovens, de permitir-lhes participação e voz na sociedade, pois somente assim reconhecerão os seus direitos, deveres e atrairão para si as suas responsabilidades sociais. Sobre essa perspectiva de direitos e deveres, Groppo (2004, p. 11) coloca que a juventude "[...] trata-se de uma categoria social usada para classificar indivíduos, normatizar comportamentos, definir direitos e deveres". Para Abramo, Souto, Facchinni e Nascimento (2009) a transição da juventude para a idade adulta era marcada pelo processo de passagem do período de escolarização para o mundo do trabalho, todavia as mudanças que se colocam nos dias atuais, não permitem mais ter marcos precisos ou constantes.

Mesmo sendo uma categoria com características generalizantes, existem várias possibilidades de se viver essa juventude. Portanto, o contexto em que o jovem está inserido pode pré-definir sua vivência social e suas experiências.

\section{$2 \mathrm{O}$ ser jovem em contexto escolar violento}

A escola é um dos espaços sociais onde essas violências, simbólicas ou não, também se reproduzem, espelhando o que se vive no contexto social geral. Por conseguinte, é necessário discutir as questões da realidade e do contexto como explica Ponce (2000, p. 93): “[...] muitas vezes a escola reproduz um modelo que não lhe é próprio, perdendo-se de suas funções prioritárias, deixando de construir a sua identidade de instituição mediadora na construção da cidadania." As autoras Zaluar e Leal (2001, p. 157) trabalham os conceitos de violência extramuros e intramuros colocando que o impacto de ambas sobre a juventude é a destruição da vida e da civilidade:

\footnotetext{
Os depoimentos e os dados apresentados ressaltam o confronto entre a violência física extramuros (na rua) e a violência intramuros, praticada na escola, demonstrando que as formas tradicionais de educação moral, até então presentes nas escolas públicas, não têm sido suficientes para impedir a invasão da escola pelos códigos e práticas que dominam as ruas das áreas pobres. O saldo desse confronto, que pode ser identificado nas estatísticas oficiais de mortalidade e nas violências as mais diversas cometidas contra a população jovem dessas áreas, sem registro, tem sido favorável aos responsáveis pela destruição de laços de civilidade e de vidas.
}

A escola, enquanto espaço do saber, deve discutir essa problemática que tanto impacta negativamente os jovens que dela fazem parte e constituem a comunidade escolar. Contudo, Martín 
et al. (2004), afirmam que a violência que se materializa na escola nem sempre terá soluções restritas a esse cenário, demandando, por vezes, ações mais abrangentes, em especial as de caráter preventivo.

Mesmo não sendo capaz de solucionar sozinha as problemáticas da violência e juventude, a escola deve enfatizar os elementos que nos humanizam. Por isso é importante refletir sobre o que coloca Ponce (2000, p. 92): "Podemos estar aprendendo a fazer da vida uma 'corrida do ouro', sem estarmos nos dando conta disso. A escola, portanto, tem de estar atenta a essas questões." A instituição e seus educadores devem convergir nos interesses para a construção de uma convivência cidadã, que possibilite uma sociedade mais humana, igualitária e socialmente justa:

[...] outros autores apontam que as especificidades nacionais devem ser consideradas para o desenho de políticas. Contudo, enfatizam a importância da educação formal e informal e serviços de atenção especializados voltados para "convivência cidadã", conjugando participação com responsabilidades sociais, resgate da confiança nas instituições, espaços de socialização e abertura de oportunidades para atividades culturais, integração comunitária e trabalhos com a família, entre outros, além das clássicas fórmulas por emprego e matrícula escolar. (CASTRO, 2002, p. 15)

A educação não é apenas o processo de aprendizagem de conhecimentos científicos, mas um processo muito mais amplo de construção de cidadania, que tem que abranger políticas públicas voltadas às demandas dessa categoria social. Por conseguinte, o espaço escolar deve ser pensado de forma que promova o desenvolvimento destes jovens. Então podemos questionar:

\footnotetext{
Que características deveria possuir tal atendimento? Qual seria a escola adequada? Sem dúvida, diante da realidade atual, torna-se premente que qualquer instituição educativa seja aberta à valorização dos interesses, conhecimentos e expectativas dos jovens favoreça sua auto-estima e consubstancie o respeito aos seus direitos em práticas e não somente na enunciação de programas e conteúdos; se proponha a motivar, mobilizar e desenvolver conhecimentos que partam da vida dos jovens e demonstre interesse por eles como cidadãos e não somente como objetos de aprendizagem. (ANDRADE; FARAH NETO, 2007, p. 76)
}

As políticas públicas educacionais precisam atender as demandas da juventude e promover estratégias efetivas para a superação das inúmeras desigualdades, pois “[...] frequentemente, quando os jovens percebem estar perdendo esse 'jogo escolar' - porque, efetivamente, não são iguais -, surgem algumas estratégias - como a própria retirada do jogo -, reconhecidas como evasão, abandono, repetência" (ANDRADE; FARAH NETO, 2007, p. 58). Os autores Andrade e Farah (2007) ainda ressaltam que vivemos hoje uma herança de aspectos negativos e positivos das políticas educacionais dos anos 1990, época na qual se estabeleceu a universalização do Ensino Fundamental, promovendo um grande avanço no quesito acesso (refletido nas matrículas); todavia, 
não possibilitou a permanência desses jovens, fato que pode ser comprovado através das estratégias criadas para jovens com mais de 15 anos.

Assim, quando a escola consegue observar as demandas dos jovens, começa a produzir formas de se contrapor a esta violência estrutural que a cerca. Seja quando estuda a realidade desses jovens, o seu entorno, o que eles pensam, promovendo assim signos e significados para a aprendizagem desses sujeitos. É preciso ainda entender a juventude como protagonista desse processo de pensar as possibilidades, alternâncias e permanências, buscando uma transformação social. A preocupação é de todos e a responsabilidade deve ser compartilhada, precisando, então,

[...] que todas as administrações do Estado, das comunidades autônomas e dos municípios, responsáveis pelos temas da educação tanto formal como não-formal, analisassem conjuntamente o fenômeno da violência entre iguais e coordenassem sua intervenção. (MARTíN et al., 2004, p. 122)

Os jovens também estão preocupados com as questões que envolvem o trabalho e o futuro. Com base nas palavras de Silva (2019), existe uma dicotomia que envolve o trabalho desses jovens, pois ao mesmo tempo que ele possibilita condições materiais de sobrevivência, também compromete o tempo para os estudos. Esses jovens mesmo que tenham mais anos de estudos que seus pais, isso não é garantia de um futuro melhor, uma vez que

\begin{abstract}
A busca incansável pela escola demonstra que os jovens estão cientes dos valores que regem a complexa sociedade em que vivem. Se, por um lado, a escolaridade não garante hoje a inserção no mercado de trabalho, especialmente em níveis sociais mais valorizados, por outro, ela impõe situações mais fortes de exclusão para quem não consegue o mínimo, como o Ensino Fundamental. (ANDRADE; FARAH NETO, 2007, p. 75)
\end{abstract}

Fica evidente que os jovens têm preocupações com o futuro, pois educação de qualidade ainda é um desafio, principalmente para os mais pobres. Portanto, é fundamental que a educação esteja engajada em proporcionar uma formação cidadã, humanista e justa, que busque a equiparação das desigualdades e possibilite oportunidades iguais para esses jovens, uma vez que

[...] o processo de escolarização constitui hoje, sem dúvida, um espaço importante de sentido, que explicita, de forma incisiva, desigualdades e oportunidades limitadas que marcam expressivos grupos de jovens brasileiros. Ao mesmo tempo, é um espaço fundamental de reflexão e luta por direitos. (ANDRADE; FARAH NETO, 2007, p. 56)

\title{
Considerações Finais
}

A sociedade estabelece várias predefinições para o ser jovem, definições essas que estabelecem o local onde esse grupo será colocado enquanto categoria (GROPPO, 2004; CARRANO, 2000). A juventude brasileira atual é exaustivamente comparada com a juventude de 
outras épocas (PONCE, 2000) como forma de demonstrar que no passado a juventude tinha mais respeito, moral, obrigações... Não se olha para esse tempo longínquo como um momento de pouca ou nenhuma liberdade. Portanto, qualquer comparação com a juventude dos tempos atuais será desleal.

Ao mesmo tempo, há várias formas de viver essa juventude. Olhando para os jovens do Brasil (BARBER-MADDEN; SABER, 2016; CASTRO, 2002) observa-se que, para eles, esse período de suas vidas é um momento de transição e de grandes desafios. Um dos principais desafios é a violência que os rodeia e cerceia muitas possibilidades e sonhos para o futuro. Enquanto espaço de convivência desses jovens, a escola deveria proporcionar a eles formas de superar essas violências que permeiam o seu cotidiano, como perguntam Andrade e Farah Neto (2007, p. 77): "Será que esses jovens não seriam portadores de novas trajetórias educacionais e de vida, se postos diante de oportunidades diferentes?" Acreditamos que sim, que o espaço escolar pode auxiliar no processo de desenvolvimento da autonomia e do protagonismo juvenil, buscando, desta maneira, possibilitar que esses jovens tenham uma vivência social saudável e cidadã, onde sejam levados a sério!

\section{Referências}

ABRAMO, Helena; SOUTO, Anna Luiza Saller; FACCHINI, Regina; NASCIMENTO, Erica. Relatório nacional Brasil: pesquisa sobre juventudes no Brasil. Instituto Brasileiro de Análises Sociais e Econômicas (iBase)/Instituto de Estudos, Formação e Assessoria em Políticas Sociais (Pólis), 2009. Disponível em: https://www.ibase.br/userimages/Brasil_ultimarev.pdf. Acesso em: 10 jan. 2021.

ANDRADE, Eliane Ribeiro; FARAH NETO, Miguel. Juventudes e Trajetórias Escolares: conquistando o direito à educação. In: ABRAMOVAY, Miriam; ANDRADE, Eliane Ribeiro; ESTEVES, Luiz Carlos Gil (Orgs.). Juventudes: outros olhares sobre a diversidade. Brasília: Ministério da Educação, Secretaria de Educação Continuada, Alfabetização e Diversidade; Unesco, 2007. p. 5578. Disponível em:

https://bibliotecadigital.mdh.gov.br/jspui/bitstream/192/160/1/MECUNESCO_juventudesou trosolharessobreadiversidade_2007.pdf. Acesso em: 8 jan. 2021.

BARBER-MADDEN, Rosemary; SABER, Bruno Abe. A situação dos jovens no mundo. In: BARBER-MADDEN, Rosemary.; SANTOS, Taís de Freitas. (Orgs.) A juventude brasileira em contexto atual e em cenário futuro. UNFPA - Fundo de População das Nações Unidas; Caixa Seguros; Secretaria Nacional de Juventude; Universidade de Brasília, 2016. p. 17-39. Disponível em: http://www.unfpa.org.br/Arquivos/livro_juventude.pdf. Acesso em: 26 maio 2020.

CARRANO, Paulo. Juventudes: as identidades são múltiplas. Movimento: Revista da Faculdade de Educação da UFF. RJ: DP\&A Editora, n. 1, maio 2000. p. 1-8. Disponível em: 
https://periodicos.uff.br/revistamovimento/article/view/32415. Acesso em: 10 jun. 2020. DOI: https://doi.org/10.22409/mov.v0i01.189

CASTRO, Mary Garcia. Violências, juventudes e educação: notas sobre o estado do conhecimento. Revista Brasileira de Estudos de População, Castro, v. 19, n. 1, jan./jun. 2002. p. 5-28. Disponível em: https://www.rebep.org.br/revista/article/view/328. Acesso em: 10 jun. 2020.

CHORÃO; CHAMPIGNON; PELADO; NEGRA LI. Não é sério. In: Nadando com os tubarões. Intérprete: Charlie Brown Jr e Negra Li. São Paulo: Virgin Records, c2000. 1CD. Faixa 3 (4 min 50).

D'AGOSTINI, Adriana; NOGARA JUNIOR, Gilberto; MARCASSA, Luciana Pedrosa. Juventude e periferias urbanas: Perfil, cultura e outros aspectos da vida social e afetiva. Revista Pedagógica (Revista do Programa de Pós-Graduação em Educaşão da Unochapecó), v. 19, n. 41, p. 137-153, maio/ago. 2017. Disponível em: https://bell.unochapeco.edu.br/revistas/index.php/pedagogica/article/view/3785. Acesso em: 4 jan. 2021. DOI: https://doi.org/10.22196/rp.v19i41.3785

D'AGOSTINI, Adriana; NOGARA JUNIOR, Gilberto; MARCASSA, Luciana Pedrosa. Cultura e vida social e afetiva subsumida à lógica de produção e reprodução do capital: o caso da juventude pobre do maciço do Morro da Cruz. In: MARCASSA, Luciana Pedrosa; CONDE, Soraya Franzoni; DALMAGRO, Sandra Luciana (Org.). Juventude pobre e escolarização: trabalho, cultura e perspectiva de futuro nos territórios do maciço do Morro da Cruz - Florianópolis. Florianópolis: Editora Em Debate, 2019. p. 427-448. Disponível em: https://editoriaemdebate.ufsc.br/catalogo/wp-content/uploads/LUCIANA-MORRO-DACRUZ-E-BOOK.pdf. Acesso em: 29 jun. 2021.

GIL, Antonio Carlos. Métodos e técnicas de pesquisa social. 6. ed. São Paulo: Atlas, 2008.

GROPPO, Luís Antônio. Dialética das Juventudes modernas e contemporâneas. Revista de Educação do COGEIME, v. 13, n. 25, p. 9-22, 2004. Disponível em: https://www.metodista.br/revistas/revistas-cogeime/index.php/COGEIME/article/view/629. Acesso em: 21 abr. 2020. DOI: http://dx.doi.org/10.15599/0104-4834/cogeime.v13n25p9-22

MARTÍN, Elena; DEL BARRIO, Cristina; MONTERO, Ignacio; FERNÁNDEZ, Ignacio; GUTIÉRREZ, H.; OCHAÍTA, Esperanza. A violência na escola. In: MARCHESI, Álvaro; GIL, Carlos Hernández. (Orgs.) Fracasso escolar: uma perspectiva multicultural. Porto Alegre: ArtMed, 2004. p. 111-123.

PONCE, Branca Jurema. Um olhar sobre a ética e o compromisso. Revista do projeto Salto para o Futuro - Um olhar sobre a escola. BRASIL. vol. 12. Ministério da Educação. Secretaria Especial de Educação a Distância. Brasilia: SEED, 2000. p. 89-96.

SEVERINO, Antônio Joaquim. Metodologia do trabalho científico. 23. ed. rev. e atual. São Paulo: Cortez, 2007.

ZALUAR, Alba; LEAL, Maria Cristina. Violência extra e intramuros. Revista Brasileira de Ciências Sociais (RBCS), São Paulo, v. 16, n. 45, p. 145-164, fev. 2001. Disponível em:

https://www.scielo.br/pdf/rbcsoc/v16n45/4335.pdf. Acesso em: 3 abr. 2021. 